\title{
Peritoneal Carcinomatosis and Mimicking on CT Scan Findings
}

\author{
Devy Yuspita Rahma \\ Radiology residency, Department of Radiology, Dr Soetomo General Academic Hospital, Faculty of Medicine, \\ Universitas Airlangga, Surabaya, Indonesia \\ Email: devyuspita@gmail.com \\ Muhammad Hidayat Surya Atmaja \\ Staff of Radiology Department, Dr Soetomo General Academic Hospital, Faculty of Medicine, Universitas \\ Airlangga, Surabaya, Indonesia \\ Corresponding author email: hidayatsuryaatmaja@gmail.com
}

\begin{abstract}
Peritoneal carcinomatosis (PC) is a term to describe the distant spread (metastatic) of the primary tumor to the peritoneal cavity. PC is a late-stage manifestation of various gastrointestinal malignancies in general and affects the ovaries, which is characterized as tumor deposits involving the surface of the peritoneal wall. If no primary signs are found, the primary diagnosis can be considered from the peritoneum itself. PC itself can be found incidentally on imaging, which can be seen on computed tomography examination, but in some mimicking images making it difficult to make a diagnosis, it is necessary to correlate it with the histopathological results.

Keywords---computed tomography, differential diagnosis, histopathology, peritoneal carcinomatosis, tumor
\end{abstract}

\section{Introduction}

Peritoneal carcinomatosis is a manifestation of metastases in various organs due to malignancy, partly due to malignancies in the GIT (gastrointestinal and ovarian, which should be noted if the cause is not known then it can be considered as the primary possibility (Cho \& Kim, 2020). Several neoplastic and non-neoplastic conditions give peritoneal mimicking carcinomatosis on CT scan, including pseudomyxoma peritonei, GIST, primary tumor metastases, granulomatous infections such as tuberculosis, and primary peritoneal malignancies such as mesotheliom (Cho \& Kim, 2020; Levy et al., 2009).

Understanding the route of spread of peritoneal carcinomatosis and the dynamics of circulation in the peritoneal is the basic thing needed to better understand the signs of peritoneal carcinomatosis itself, which has four routes of spread (Diop et al., 2014; Pickhardt \& Bhalla, 2005):

- Hematogenous is the main route in primary tumors with high malignancy capable of invading the walls of blood vessels, then spread and implant in the peritoneum by vascular permeability factor (VPF) which can increase capillary permeability (Bijek et al., 2011).

- Contiguous spread locally or regionally, originating from a large tumor penetrating the serous layer and invading surrounding organs

- Lymphatic route

There are two routes of lymphatic spread, namely through the lymphatic system of the greater omentum and the right-sided subphrenic. Tumor cells will be trapped and follow the flow of the lymphatic chain in the anterior mediastinum to the right lymphatic duct and subclavian vein. When the flow of the subphrenic lymphatic system is obstructed, ascites occur due to peritoneal fluid barriers that cannot be reabsorbed.

- Spread to the peritoneal surface

Secondary redistribution to gravity, implanted carcinomatosis in the superior part of the sigmoid mesocolon, inferior part of the mesentery, ileocaecal junction, Cavum of Douglas, and right paracolic gutter. Peristaltic 
movements bring the carcinomatosis along with the peritoneal circulation along the paracolic gutter and then back across the lower surface of the diaphragm, implantation in Morrison's pouch, bursa omentum, and along the left paracolic gutter (Sohail et al., 2022; Rivard et al., 2014; Nurman et al., 2021).

\section{Discussion}

Peritoneal carcinomatosis without distant spread is a locoregional disease that requires aggressive treatment. On contrast examination, the thickening of the parietal peritoneal wall appears enhanced, where the peritoneum will look like a thin line along the abdominal wall, as well as the presence or absence of ascites. On CT examination, other signs that need attention in peritoneal carcinomatosis are (Diop et al., 2014; Pickhardt \& Bhalla, 2005):

- Ascites, non-specific, free, or loculated, accounts for almost 70\% of cases (Chang et al., 2005).

- Greater omentum involvement. Tumors involving the omentum are seen as dense fat, enhanced nodules, advanced forms of omental fat will be replaced by a solid mass that separates the colon or small intestine from the anterior abdominal wall, which is referred to as the omental "cake"

- Invasion of the mesentery

Invasion of the mesentery may manifest as gastric wall thickening, increased mesenteric fat density, the presence of a "stellate" mesenteric mass, or one or more confluent mesenteric nodules.

- Implantation of the tumor into the peritoneal wall. CT scan shows nodular formation or diffuse thickening of the serous layer of the peritoneum, which is enhanced on contrast administration, whereas indirect signs show adhesions of the small intestine or bowel segments becoming fixed to the wall, which impedes the free circulation of ascitic fluid. Involvement of the visceral peritoneum is evident in the perihepatic ligament rotundum and subphrenic space, where it can mimic liver metastases, causing scalloping of the liver surface (Diop et al., 2014; Lau et al., 2004; Yajima et al., 2006).

In this paper, based on our experience at Dr. Soetomo Hospital, Surabaya with patients who have had a CT scan with a mimicking peritoneal carcinomatosis image and confirmed histopathologically.

\section{Pseudomyxoma peritonei}

Pseudomyxoma peritonei (PP) is a clinical and radiological term, not a pathological term. refers to where the mucinous fluid material in large quantities extends into the peritoneal cavity. PP usually originates from a mucinous appendix malignancy in men and mucinous ovarian tumors in women, and the fluid may or may not be accompanied by cancer cells based on the primary lesion. On CT images the mucin form in the peritoneal cavity usually shows a hypodense-looking fluid that is equivalent to attenuation almost like soft tissue and omental haziness. The form of scalloping on the visceral surfaces of intraperitoneal organs, which indicates extrinsic pressure from mucinous implantation, is a typical form of PP (Seshul \& Coulam, 1981).

Case 1: A 54-year-old woman, pseudomyxoma peritonei with complaints of abdominal pain and swelling. 

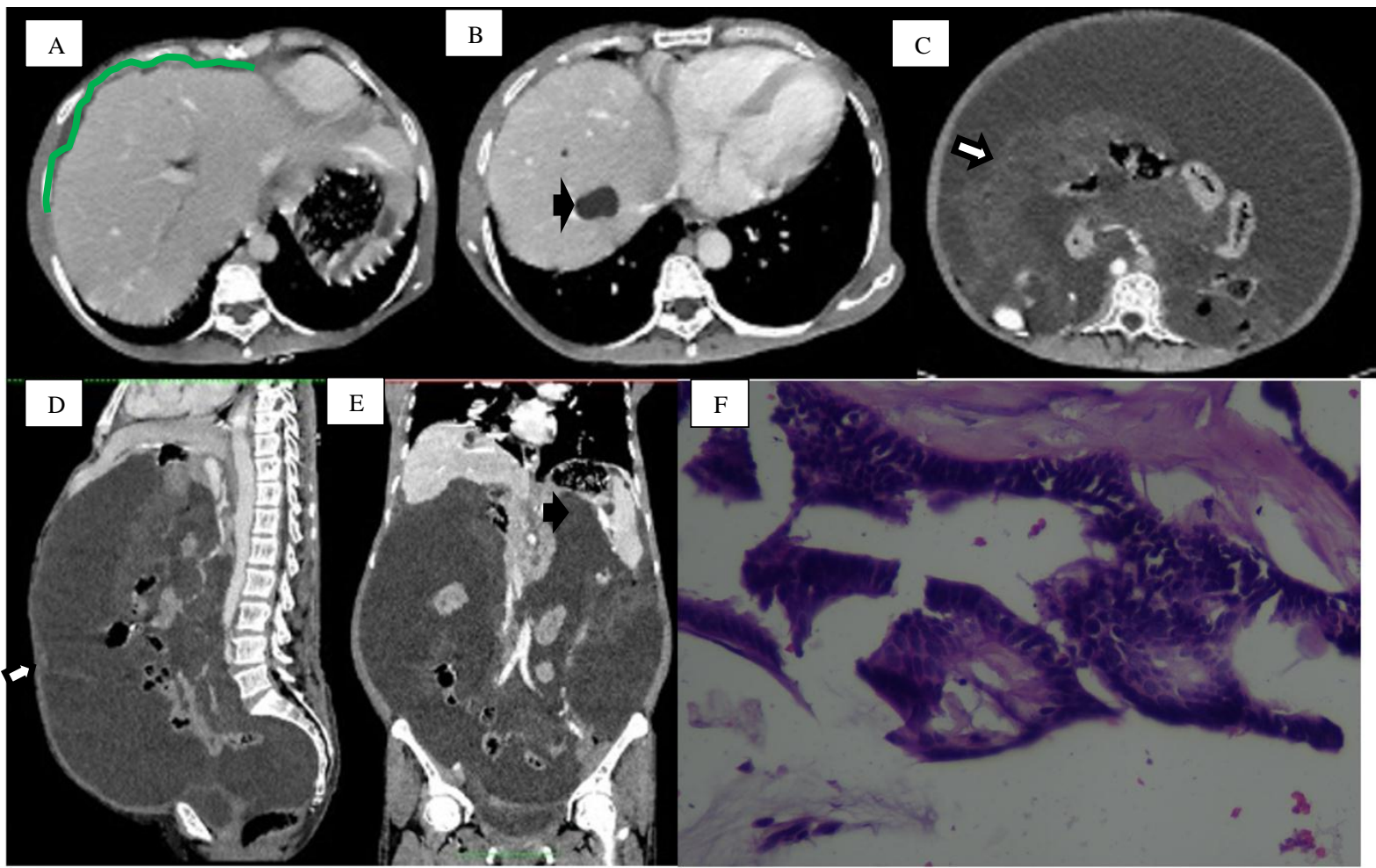

Figure 1. Axial, sagittal, coronal CT scan of the abdomen (A, B, C, D, E) with contrast showing irregularity and scalloping of the liver margins (green line) with diffuse omental thickening with bowel wall thickening (white arrows). Multiple cystic nodules are also found in the perihepatic and perispleenic and lymphadenopathy in the paracava. The patient with a history of post-SVH-BSO ovarian ca 4 years ago, did not have a residual mass on the surgical bed. Biopsy examination and paraffin block 400x (F) showed the distribution of extracellular mucin material, consisting of proliferation of cuboidal columnar epithelial cells with round oval nuclei at the base, some hyperchromatic with prominent nucleoli, extensive cytoplasm containing mucin vacuoles according to pseudomyxoma peritonei.

\section{Secondary tumor of the peritoneum (Metastatic)}

Secondary seeding of the peritoneum is iatrogenic during surgery or biopsy when tumor spillage into the peritoneal cavity during surgical resection or when tumor cells or emboli exit the lymphatic channels at the surgical site or the periphery. Once in the peritoneal cavity, tumor cells that are free (floating) will migrate through the peritoneal cavity by passing through the normal fluid circulation. Tumor cells initially tend to coalesce in the peritoneum, depending on the gravity and the area of stasis of the peritoneum and subdiaphragmatic space, in the end, the tumor deposits diffusely adhere to the visceral and parietal peritoneum. Direct invasion into the peritoneal cavity results in periodic extension of the malignancy. On a CT scan, ascites are found with varying fluid density, can be thick which describes the content of exudate, both free and loculated, accompanied by thickening of the walls and peritoneal nodules. The spread of the tumor to the peritoneum causes a fibrotic response to tumor growth and invades the subperitoneal tissue, consequently, the omental fat is replaced by fibrotic tissue and the tumor appears omental caking on CT. If a tumor infiltrates the perivascular space causing the vasculature in the mesentery to appear denser than normal mesenteric fat, which gives a star-like appearance in the sky, it is called a "stellate mesentery" (Chang et al., 2005; Walkey et al., 1988).

Case 2: 49-year-old woman with complaints of an enlarged abdomen. Ovarian Ca history has been done TAH-BSO 


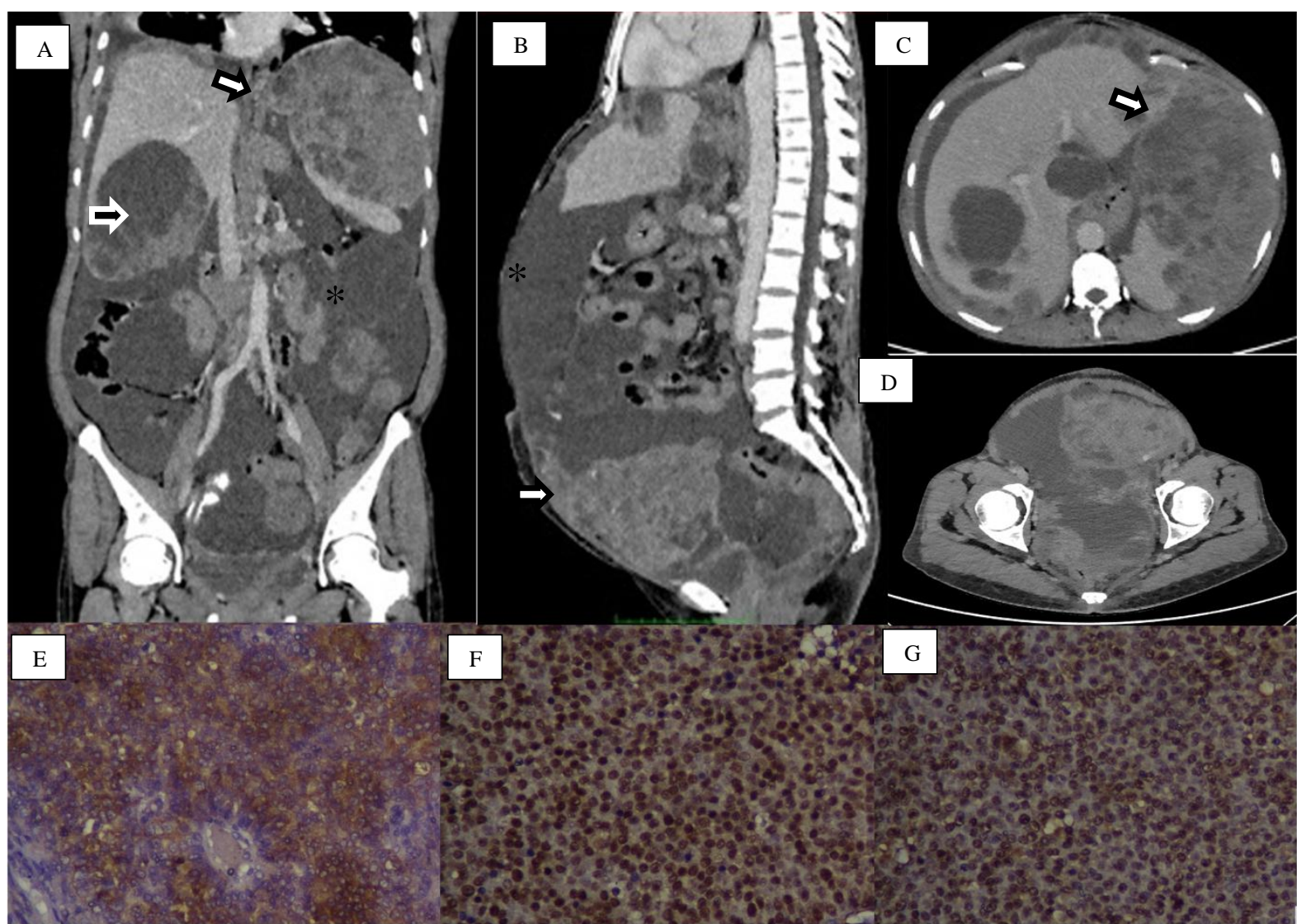

Figure 2. CT abdominal vein in axial, coronal, and sagittal sections (A, B, C, D) shows peritoneal carcinomatosis with omental cake in the left hypochondrium region and multiple peritoneal nodules in the right posterior lumbar region (white arrow), fat stranding (+). Ascites with thick fluid density (asterisk) and multiple mass metastases in the liver (black arrow), then surgery and tumor biopsy (omental cake) (E, F, G) showed anaplastic cell proliferation, mitoses 28/10 HPF according to adult granulosa metastases tumor cells

\section{Tuberculous peritonitis}

Tuberculosis can involve the peritoneum and will spread to the peritoneal cavity in many ways, including systemic infection, a direct extension of the hollow viscus to the peritoneum, or lymphogen. If this happens, the diagnosis of tuberculous peritonitis can be made. On CT examination, a soft tissue mass or nodule in the peritoneal cavity was seen, retroperitoneal lymphadenopathy with central necrotic, ascites, and omental infiltration, which was mimicking on PC. Although small abscesses in the liver and spleen can be distinguished from PC, the lymph nodes and spleen with calcifications and splenomegaly on CT indicate tuberculous peritonitis. Tuberculous peritonitis is distinguished by wet type (wet type), fixed fibrotic and dry type (dry type). The wet type shows free or loculated ascitic fluid with septation. While the fixed fibrotic type showed omental and mesenteric masses, the dry type showed peritoneal wall thickening and necrotic lymph nodes. Peritoneal thickening is smoother on the surface than nodular lesions in peritoneal carcinomatosis (Y1lmaz et al., 2002; Akhan \& Pringot, 2002).

Case 3: A man 34-years old with complaints of flatulence and swelling of both legs. The patient is known to be on TB treatment for 2 weeks 


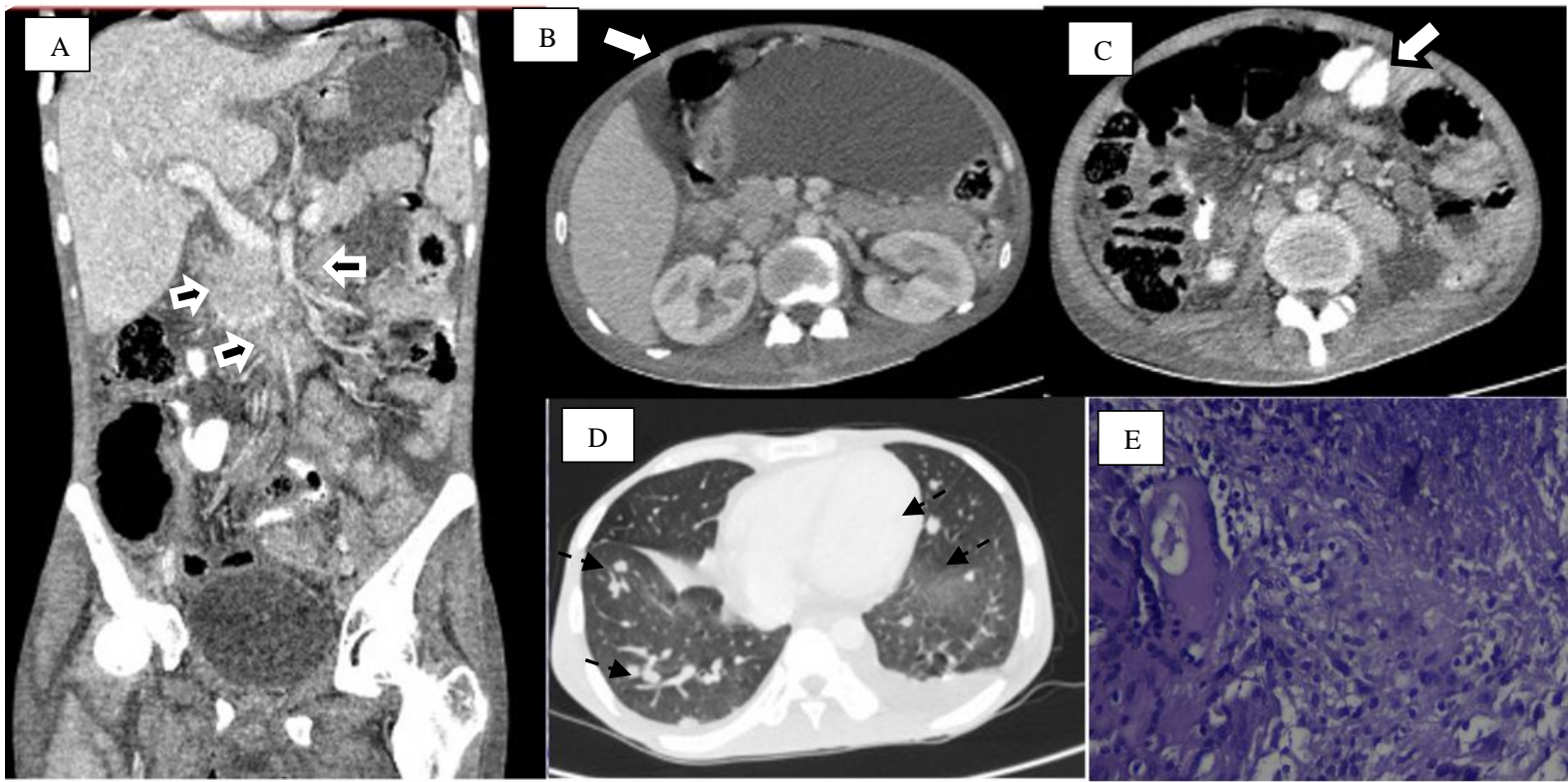

Figure 3. On abdominal CT examination with contrast axial, sagittal venous phase (A, B, C) there was free fluid in the bowel loop with thickening of the peritoneal wall, diffuse (white arrow) and omental haziness, accompanied by multiple lymphadenopathies with central necrotic in the mesenteric, paraaortic, paracava to parailiaca (black arrow) showing PC mimicking; multiple nodules in both lung fields were seen as tuberculomatosis (dotted arrow). HistoPA examination of paraffin block 400x (E) showed datia Langhans cells with granulomas with caseous necrosis

\section{Primary peritoneal malignant mesothelioma (PMM)}

It is a rare but aggressive neoplasm with mesothelial origin or mesenchymal cells of the pleura, pericardium, and peritoneum. Most mesothelioma originates from the pleura, 6-10\% originates from the peritoneum, manifests as a large tumor mass (dry type) or confluent either nodular or diffuse, may or may not be accompanied by ascites and thickening of the peritoneum which is a "wet type" picture. Calcifications are generally rare. It is difficult to distinguish PC from this PMM if only relying on one imaging examination. A history of exposure to asbestosis was found in some cases with a pleural plaque appearance, which can differentiate PMM from PC. On microscopic examination, hyperchromatic nuclei and large cells with peripheral dense cytoplasm were found (Gilly et al., 2006; Lin et al., 2020; De Bree et al., 2006).

\section{Desmoplastic small round cell tumor}

Is a very aggressive neoplasm involving the peritoneal cavity, occurs in young adults. CT images may manifest as round, multiple masses in the peritoneum with or without ascites. In contrast administration, heterogeneous enhancement with central-low attenuation appears. The omentum and the paravesical region are also involved, whereas the appearance of diffuse peritoneal thickening is a rare infiltrative manifestation (Casanova et al., 2021; Dohan et al., 2014; Shliakhtunou et al., 2021).

Case 4: A male patient aged 43 years with complaints of enlarged stomach for 8 months accompanied by difficulty in defecating and urinating 

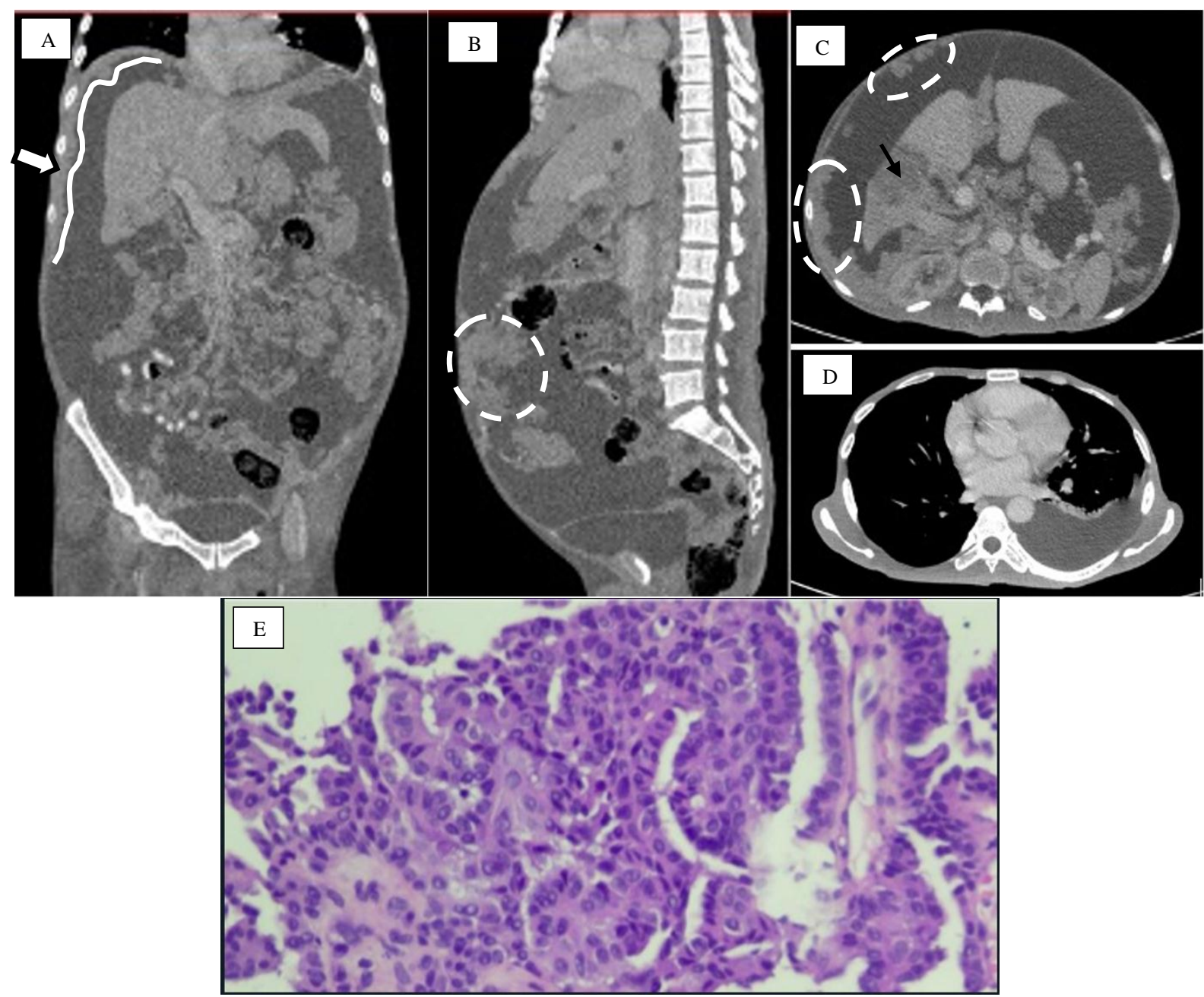

Figure 4. On abdominal CT examination coronal, sagittal, axial slices with contrast in the venous phase (A, B, C, D). There is an enhancing thickening with irregularities (white arrows) on the peritoneal wall accompanied by multiple mesenteric nodules (white dotted line) in the abdominal cavity to the pelvis and solid metastatic nodules in segment VI (black arrow). (D) The left lung base shows a pleural effusion. (E) Biopsy and immunohistochemistry examinations were performed, showing a malignant round cell tumor with a differential diagnosis of mesothelioma and adenocarcinoma presumably of hepatobiliary origin, a further immunohistochemical examination was recommended, but the patient died.

\section{GIST (Gastrointestinal Stromal Tumor)}

GIST is a rare visceral malignancy originating from the wall of the gastrointestinal tract. This tumor originates in the muscular and muscular propria mucous layers anywhere from the esophagus to the rectum. Peritoneal involvement due to GIST or leiomyosarcoma is a common primary GI site for metastatic spread. GIST malignancy is characterized by an extraluminal solid mass, $>5 \mathrm{~cm}$ in size, well-circumscribed, heterogeneous with a necrotic center within the tumor, sometimes accompanied by bleeding, necrosis, or cystic degeneration. Most masses originate from the stomach $(60-70 \%)$ followed by the small bowel (20-25\%) and most rarely from the rectum (5\%), esophagus, colon, and appendix (Walkey et al., 1988). GIST rarely originates in the mesentery, omentum, and retroperitoneum, which may occur with large size. One distinguishing GIST is hypervascularization with peripheral enhancement with dilatation of the surrounding vasculature (Smiti \& Rajagopal, 2010).

Case 5: Female patient / 48 years old with suspected malignant ovarian tumor with complaints of the enlarged abdomen, decreased appetite. The patient underwent a previous abdominal ultrasound examination with suspicion of a solid mass exceeding the probe diameter $+/-18 \mathrm{~cm}$ with a necrotic component in it, difficult to determine the 
boundaries of the uterus. The results of the examination of the tumor marker CA $125(147 \mathrm{U} / \mathrm{mL})$ and increased LDH.

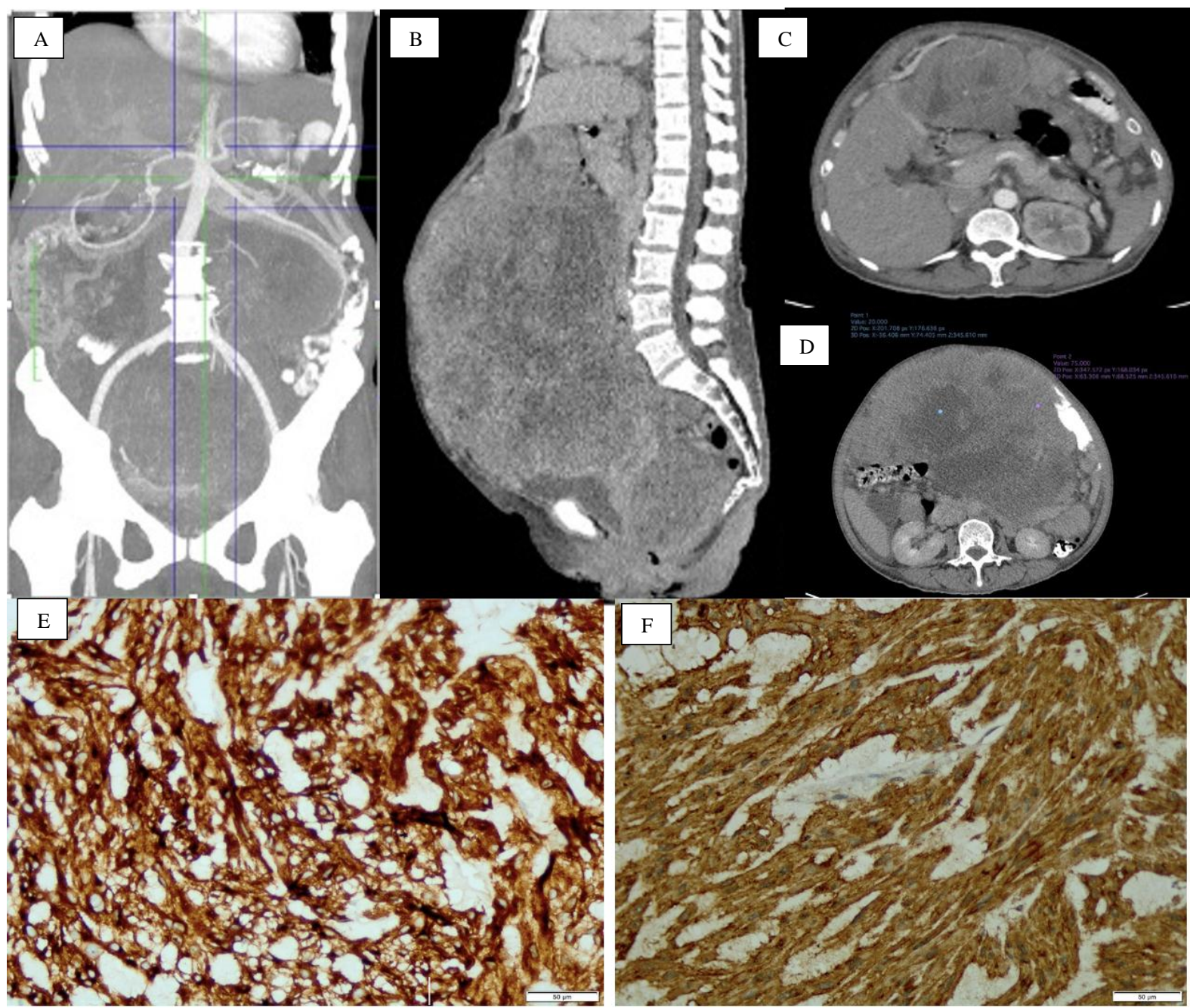

Figure 5. Axial, sagittal, and coronal (A, B, C, D)Abdominal CT shows a large heterogeneous solid mass with necrotic and cystic components with an impression originating from the GI tract, with a feeding artery branch a. mesenteric, accompanied by peritoneal carcinomatosis with features of ascites and multiple peritoneal nodules. The uterus seems good. After immunohistochemical examination (E, F) markers CD 117 and DOG-1 were obtained according to the GIST

\section{Conclusion}

Although this peritoneal carcinomatosis has many mimicking patterns found on CT scans, it can still be distinguished by specific signs where the findings of scalloping on the visceral surface of the intraperitoneal organs, extensive lymph node enlargement, history of exposure to asbestosis, or visible plaques on the pleura are not found in the patient. case number 1 with pseudomyxoma peritonei. A history of primary ovarian cancer or uterine leiomyoma is also the primary cause, this is the biggest challenge to differentiate between peritoneal carcinomatosis and tuberculous peritonitis because the treatment will be different, so as a radiologist, you must be able to differentiate each on imaging. 
Table 1

Primary malignant peritoneal

\begin{tabular}{|c|c|c|c|c|c|c|}
\hline & \multirow[b]{2}{*}{$\begin{array}{l}\text { Pseudomyxoma } \\
\text { Peritonei }\end{array}$} & \multirow[b]{2}{*}{$\begin{array}{l}\text { Tuberculous } \\
\text { Peritonitis }\end{array}$} & \multicolumn{3}{|c|}{ Primary Malignant Peritoneal } & \multirow[b]{2}{*}{ Metastatic } \\
\hline & & & Mesothelioma & $\begin{array}{l}\text { Desmoplastic } \\
\text { Small Round } \\
\text { cell Tumor }\end{array}$ & GIST & \\
\hline $\begin{array}{l}\text { Peritoneal wall } \\
\text { thickening }\end{array}$ & + & $\begin{array}{l}\text { + diffuse, } \\
\text { smooth }\end{array}$ & + & $\begin{array}{l}+/- \\
\text { (diffuse, rare) }\end{array}$ & + & $\begin{array}{l}+ \\
\text { irregular }\end{array}$ \\
\hline Omental cake & + & + & $\begin{array}{l}\text { +/- with } \\
\text { mesenteric } \\
\text { mass }\end{array}$ & $\begin{array}{l}+/ \text { - } \\
\text { (less common) }\end{array}$ & & $\begin{array}{l}+ \\
\text { (Later } \\
\text { form) }\end{array}$ \\
\hline Lymphadenopathy & & $\begin{array}{l}+ \\
\text { (central } \\
\text { necrotic) }\end{array}$ & - & - & $+/-$ & \\
\hline Ascites & Mucinous & $\begin{array}{l}+(\text { wet type }) \\
\text { free or } \\
\text { loculated }\end{array}$ & $+/-$ & $+/-$ & + & $\begin{array}{l}+ \text { (present } \\
\text { in } 70 \% \text { of } \\
\text { cases), } \\
\text { free or } \\
\text { loculated }\end{array}$ \\
\hline $\begin{array}{l}\text { Scalloping of the } \\
\text { visceral surface }\end{array}$ & + & Absent & Absent & Absent & Absent & Absent \\
\hline Peritoneal nodul & + & + multiple & $\begin{array}{l}\text { Large mass } \\
\text { nodular/ } \\
\text { diffuse }\end{array}$ & $\begin{array}{l}\text { Rounded, } \\
\text { heterogenous } \\
\text { contrast } \\
\text { enhanced with } \\
\text { central } \\
\text { hipoattenuation }\end{array}$ & $\begin{array}{l}\text { Lebih } 5 \mathrm{~cm} \\
\text { Well- } \\
\text { circumscribed } \\
\text { Heterogenous } \\
\text { with central } \\
\text { necrotic }\end{array}$ & + \\
\hline $\begin{array}{l}\text { Mesenteric } \\
\text { features }\end{array}$ & Rare & + & $+/-$ & & Rare & $\begin{array}{l}\text { Stellate } \\
\text { masses (+) }\end{array}$ \\
\hline $\begin{array}{l}\text { History of } \\
\text { asbestosis and } \\
\text { pleural plaque }\end{array}$ & - & - & + & - & - & - \\
\hline Calcification & Curvilinear & + & $\begin{array}{l}+ \\
\text { rare }\end{array}$ & - & - & - \\
\hline
\end{tabular}

\section{References}

Akhan, O., \& Pringot, J. (2002). Imaging of abdominal tuberculosis. European radiology, 12(2), 312-323.

Bijek, J. H., Ehnart, N., \& Mathevet, P. (2011). Hematogenous dissemination in epithelial ovarian cancer: Case report. Journal de Gynecologie, Obstetrique et Biologie de la Reproduction, 40(5), 465-468.

Casanova, J., Jurgiel, J., Henriques, V., Nabais, H., Pinto, L. V., \& Cunha, J. F. (2021). Peritoneal deciduosis mimicking peritoneal Carcinomatosis: A case report. Gynecologic Oncology Reports, 37, 100827. https://doi.org/10.1016/j.gore.2021.100827

Chang, D. K., Kim, J. W., Kim, B. K., Lee, K. L., Song, C. S., Han, J. K., \& Song, I. S. (2005). Clinical significance of CT-defined minimal ascites in patients with gastric cancer. World Journal of Gastroenterology: WJG, 11(42), 6587.

Cho, J. H., \& Kim, S. S. (2020). Peritoneal carcinomatosis and its mimics: review of CT findings for differential diagnosis. Journal of the Belgian Society of Radiology, 104(1).

De Bree, E., Koops, W., Kröger, R., Van Ruth, S., Verwaal, V. J., \& Zoetmulder, F. A. N. (2006). Preoperative computed tomography and selection of patients with colorectal peritoneal carcinomatosis for cytoreductive surgery and hyperthermic intraperitoneal chemotherapy. European Journal of Surgical Oncology (EJSO), 32(1), 65-71. https://doi.org/10.1016/j.ejso.2005.09.016 
Diop, A. D., Fontarensky, M., Montoriol, P. F., \& Da Ines, D. (2014). CT imaging of peritoneal carcinomatosis and its mimics. Diagnostic and interventional imaging, 95(9), 861-872.

Diop, A. D., Fontarensky, M., Montoriol, P. F., \& Da Ines, D. (2014). CT imaging of peritoneal carcinomatosis and its mimics. Diagnostic and interventional imaging, 95(9), 861-872. https://doi.org/10.1016/j.diii.2014.02.009

Dohan, A., Eveno, C., Soyer, P., \& Pocard, M. (2014). Focal fatty infiltration in Segment IV of the liver mimicking peritoneal carcinomatosis on CT and MR imaging. Journal of Visceral Surgery, 151(4), 319-321. https://doi.org/10.1016/j.jviscsurg.2014.05.008

Gilly, F. N., Cotte, E., Brigand, C., Monneuse, O., Beaujard, A. C., Freyer, G., \& Glehen, O. (2006). Quantitative prognostic indices in peritoneal carcinomatosis. European Journal of Surgical Oncology (EJSO), 32(6), 597-601. https://doi.org/10.1016/j.ejso.2006.03.002

Lau, S., Tam, K., Kam, C. K., Lui, C. Y., Siu, C. W., Lam, H. S., \& Mak, K. L. (2004). Imaging of gastrointestinal stromal tumour (GIST). Clinical radiology, 59(6), 487-498.

Levy, A. D., Shaw, J. C., \& Sobin, L. H. (2009). Secondary tumors and tumorlike lesions of the peritoneal cavity: imaging features with pathologic correlation. Radiographics, 29(2), 347-373.

Lin, Y. C., Liao, C. C., \& Lai, H. C. (2020). Intraperitoneal splenosis mimics peritoneal carcinomatosis of leiomyosarcoma and ovarian cancer. Taiwanese Journal of Obstetrics and Gynecology, 59(5), 773-776. https://doi.org/10.1016/j.tjog.2020.07.028

Nurman, D. G., Karim, A. K., Akhnazarov, S. K., Mukashev, S. T., \& Demissenov, O. M. (2021). Current issues of molecular diagnostics of bladder cancer. International Journal of Health Sciences, 5(3), 286-301. https://doi.org/10.53730/ijhs.v5n3.1477

Pickhardt, P. J., \& Bhalla, S. (2005). Primary neoplasms of peritoneal and sub-peritoneal origin: CT findings. Radiographics, 25(4), 983-995.

Rivard, J. D., Temple, W. J., McConnell, Y. J., Sultan, H., \& Mack, L. A. (2014). Preoperative computed tomography does not predict resectability in peritoneal carcinomatosis. The American Journal of Surgery, 207(5), 760-765. https://doi.org/10.1016/j.amjsurg.2013.12.024

Seshul, M. B., \& Coulam, C. M. (1981). Pseudomyxoma peritonei: computed tomography and sonography. American Journal of Roentgenology, 136(4), 803-806.

Shliakhtunou, Y. A., Siamionau, V. M., \& Pobyarzhin, V. V. (2021). Transcription phenotype of circulating tumor cells in non-metastatic breast cancer: Clinical and prognostic significance. International Journal of Health Sciences, 5(3), 474-493. https://doi.org/10.53730/ijhs.v5n3.2019

Smiti, S., \& Rajagopal, K. V. (2010). CT mimics of peritoneal carcinomatosis. Indian Journal of Radiology and Imaging, 20(01), 58-62.

Sohail, A. H., Khan, M. S., Sajan, A., Williams, C. E., Amodu, L., Hakmi, H., ... \& Ahmad, M. N. (2022). Diagnostic accuracy of computed tomography in differentiating peritoneal tuberculosis from peritoneal carcinomatosis. Clinical Imaging, 82, 198-203. https://doi.org/10.1016/j.clinimag.2021.11.023

Walkey, M. M., Friedman, A. C., Sohotra, P., \& Radecki, P. D. (1988). CT manifestations of peritoneal carcinomatosis. American Journal of Roentgenology, 150(5), 1035-1041.

Yajima, K., Kanda, T., Ohashi, M., Wakai, T., Nakagawa, S., Sasamoto, R., \& Hatakeyama, K. (2006). Clinical and diagnostic significance of preoperative computed tomography findings of ascites in patients with advanced gastric cancer. The American journal of surgery, 192(2), 185-190. https://doi.org/10.1016/j.amjsurg.2006.05.007

Yılmaz, T., Sever, A., Gür, S., Killi, R. M., \& Elmas, N. (2002). CT findings of abdominal tuberculosis in 12 patients. Computerized medical imaging and graphics, 26(5), 321-325. https://doi.org/10.1016/S08956111(02)00029-0 